\title{
POLA PEMENUHAN HAK DAN KEWAJIBAN SUAMI ISTRI LONG DISTANCE RELATIONSHIP (LDR)
}

\author{
Reza Umami Zakiyah \\ Fakultas Syari'ah dan Hukum, UIN Sunan Gunung Djati Bandung \\ Email: rumamizakiyah@gmail.com
}

\begin{abstract}
Ideally, a married couple lives together to carry out their respective duties and obligations. However, because the demands of work cause some of them must be far apart and live the life of Long Distance Relationship (LDR) as happened in Batujaya Village, Kec. Batujaya, Kab. Karawang. The problem that arises is how the pattern of fulfilling the rights and obligations of husband and wife in Batujaya Village, Kec. Batujaya, Kab. Karawang. How to communicate on LDR and how to overcome the difficulties that arise between the two. Through research using descriptive analysis method, the results of the study show that: (1) The pattern of fulfilling the rights and obligations of a husband and wife who are on a LDR at Batujaya Village, Kec. Batujaya, Kab. Karawang can be understood in three aspects, namely the Financial/material aspect is done by meeting in person/transferring money through Alfamart/ATM/POS. The biological aspect when far apart is by interacting by telephone, occupying with homework. Psychological aspects, namely by giving attention over the phone or when meeting by serving all their needs. (2) The way of LDR husband and wife communication via telephone, massage, whatsapp, and video call, but for those who do not use the telephone as a communication tool, the communication is carried out directly when meeting. (3) The way to overcome the difficulties that arise between the two is to maintain mutual trust, understanding, commitment, intensive communication, mutual attitude. The difficulties faced are financial, trust, communication, cooperation and sexual needs.
\end{abstract}

Keywords: Rights, Obligations, Long Distance Relationship

\begin{abstract}
Abstrak
Idealnya pasangan suami istri hidup bersama dalam satu rumah untuk melaksanakan tugas dan kewajiban masing-masing. Namun, karena tuntutan pekerjaan menyebabkan sebagian dari mereka harus berjauhan dan menjalani kehidupan Long Distance Relationship (LDR) seperti yang terjadi di Desa Batujaya, Kec. Batujaya, Kab. Karawang. Masalah yang timbul yaitu bagaimana pola pemenuhan hak dan kewajiban suami istri di Desa Batujaya, Kec. Batujaya, Kab. Karawang. Bagaimana cara komunkasi suami istri LDR dan bagaimana cara mengatasi kesulitan yang timbul diantara keduanya. Melalui penelitian yang menggunakan metode deskriptif analisis ini, hasil penelitian menunjukan bahwa: (1) Pola pemenuhan hak dan kewajiban suami istri Long Distance Relationship (LDR) di Desa Batujaya, Kec. Batujaya. Kab. Karawang dipahami dalam tiga aspek yaitu Aspek Finansial/materi dilakukan dengan pola bertemu langsung/ mentransfer uang melalui Alfamart/ATM/POS. Aspek biologis ketika berjauhan yaitu dengan berinteraksi melalui telepon, menyibukan diri dengan pekerjaan rumah. Aspek
\end{abstract}


psikologis yaitu dengan memberikan perhatian lewat telepon ataupun saat bertemu secara langsung dengan melayani segala kebutuhan masing-masing. (2) Cara komunikasi suami istri LDR melalui telephone, sms, whatshap, dan Video call, tetapi untuk mereka yang tidak menggunakan telepon sebagai alat komunikasi, maka komunikasinya dilakukan secara langsung pada saat bertemu. (3) Cara mengatasi kesulitan yang timbul diantara keduanya yaitu saling menjaga kepercayaan, pengertian, komitmen, komunikasi intensif, sikap saling terbuka. Adapun kesulitan yang dihadapi yaitu masalah keuangan, kepercayaan, komunikasi, kerjasama dan kebutuhan seksual.

Kata Kunci: Hak, Kewajiban, Long Distance Relationship

\section{PENDAHULUAN}

Long Distance Relationship (LDR) adalah suatu hubungan dimana para pasangan yang menjalaninya dipisahkan oleh jarak dan fisik yang tidak memungkinkan adanya kedekatan fisik untuk periode waktu tertentu. ${ }^{1}$ Holt dan Stone dalam tulisan yang berjudul"A Study Of Culture Variability Andrelational Maintenance Beharviors For International And Domestic Proximal And Long Distance Interpersonal Relationship," sebagaimana dikutip oleh Thomas J. Kidenda menggunakan faktor jarak serta waktu untuk mengkatagorikan pasangan yang menjalani hubungan jarak jauh. Holt dan Stone mendapatkan informasi demografis dari partisipan penelitiannya, dan menunjukan bahwa yang menjalani hubungan jarak jauh, terbagi menjadi tiga kategori. Kategori pertama dilihat dari waktu terpisah (0-6 bulan, lebih dari 6 bulan), kategori kedua dilihat dari intensitas pertemuan (sekali seminggu, seminggu hingga sebulan, kurang dari satu bulan) dan kategori yang ketiga yaitu diihat dari jarak (0-1 mil, 2-294 mil, lebih dari 250 mil). ${ }^{2}$

Jadi dari sini dapat dipahami bahwa tidak ada ketentuan khusus yang sangat signifikan terkait waktu, jarak dan intensitas pertemuan, jika salah satu kategori diatas telah terpenuhi maka pasangan tersebut dapat dikatakan telah menjalani Long Distance Relationship (LDR). Maka yang dapat kita gali selanjutnya yaitu mengenai peran-peran apa saja yang menjadi tanggung jawab antara suami istri atau yang disebut juga

1David, P, Hampton, JR. (2004). “The Effect od Communication On Satisfaction In Long Distance And Proximal Relationships of College Students". Chicago: Loyola University. Diakses dari http://www.webclearinghouse.net/volume/4/HAMPTON-TheEffecto.php. Pada tanggal 13 mei 2018 pukul 11.15 WIB.

${ }^{2}$ Thomas, J. Kidenda,(2002)." A Study of culture variability andrelational maintenance beharviors forinternational and domestic proximal and long distance interpersonal relationship", (Doctoral Dissertation) Diakses

https://scholar.google.co.id/scholar/hl=id\&as sdt=0\%2C5\&q=kidenda+t.j+a+study+of+culture+variability+ andrelational\&btnG=\#d=g qabs\&p=\&u=\%23p\%3Do6rVg5TLibgjs, Pada Tanggal 13 Mei 2018 Pukul 10.47 WIB.

72 Jurnal Al-Ahwal Al-Syakhsiyyah : Jurnal Hukum Keluarga dan Peradilan Islam 
Reza Umami Zakiyah, Pola Pemenuhan Hak dan Kewajiban Suami Istri Long Distance Relationship ... dengan istilah hak dan kewajiban suami istri yang sedang Long Distance Relationship (LDR). Pasangan tersebut adalah sebagai berikut:

\begin{tabular}{|c|c|c|c|}
\hline NO & $\begin{array}{c}\text { NAMA } \\
\text { INFORMAN }\end{array}$ & JARAK & $\begin{array}{l}\text { INTENSITAS } \\
\text { PERTEMUAN }\end{array}$ \\
\hline 1 & $\begin{array}{c}\text { Diana Apriani } \\
\text { Dikky }\end{array}$ & $\begin{array}{l}\text { Batujaya-Bogor } \\
\text { 2 Jam } 48 \text { Menit }(102,5 \mathrm{Km}) \\
=(63,6525 \mathrm{Mil})\end{array}$ & 1 bulan sekali \\
\hline 2 & $\begin{array}{l}\text { Lita Safitri } \\
\text { Andi Wijaya }\end{array}$ & $\begin{array}{c}\text { Batujaya- Cikampek } \\
\text { (Karawang) } \\
\text { 1 Jam } 57 \text { Menit }(76,1 \mathrm{~km})= \\
(47,2581 \text { Mil })\end{array}$ & 1 bulan sekali \\
\hline 3 & $\begin{array}{c}\text { Sanja } \\
\text { Nurkinah }\end{array}$ & $\begin{array}{c}\text { Batujaya-Pasar Minggu } \\
\text { (Jakarta Selatan) } \\
\text { 2 Jam } 43 \text { Menit }( \\
\text { 142,22km })=(88,3062 \text { Mil })\end{array}$ & 1 atau 2 bulan sekali \\
\hline 4 & $\begin{array}{l}\text { Budi Kurniawan } \\
\text { Yuliana }\end{array}$ & $\begin{array}{c}\text { Batujaya - Jambi } \\
23 \text { jam } 7 \text { menit }(928,5 \mathrm{~km}) \\
=(576,5985 \mathrm{Mil})\end{array}$ & 6 bulan sekali \\
\hline 5 & $\begin{array}{c}\text { Jupri } \\
\text { Sinta Dewi }\end{array}$ & $\begin{array}{c}\text { Batujaya-Pasar Minggu } \\
\text { 2 Jam } 43 \text { Menit }(142,2 \mathrm{~km}) \\
=(88,3062 \mathrm{Mil})\end{array}$ & 1 atau 2 bulan sekali \\
\hline 6 & $\begin{array}{c}\text { Danu Miharja } \\
\text { Siti Khodijah }\end{array}$ & $\begin{array}{c}\text { Batujaya- Tanggerang } \\
3 \text { jam } 6 \text { menit }(101,1 \mathrm{~km})= \\
(62,7831 \mathrm{Mil})\end{array}$ & 1 atau 2 bulan sekali \\
\hline 7 & $\begin{array}{l}\text { Sobari } \\
\text { Rohayati }\end{array}$ & $\begin{array}{c}\text { Batujaya-Bogor } \\
\text { 2 Jam } 48 \text { Menit }(102,5 \mathrm{Km}) \\
=(63,6525 \mathrm{Mil})\end{array}$ & 6 bulan sekali \\
\hline 8 & $\begin{array}{l}\text { Japar dan } \\
\text { Hamidah }\end{array}$ & $\begin{array}{c}\text { Batujaya-Cikarang } \\
\text { 1 Jam } 31 \text { Mnit }(52,9 \mathrm{~km})= \\
(32.8509 \mathrm{Mil})\end{array}$ & 1 bulan sekali \\
\hline 9 & $\begin{array}{l}\text { Subet } \\
\text { Titi }\end{array}$ & $\begin{array}{c}\text { Batujaya-Menteng } \\
\text { (Jakarta Pusat) } \\
\text { 2 Jam } 40 \text { Menit ( } 72,3 \mathrm{Km}) \\
=(44,8983 \mathrm{Mil}\end{array}$ & 2 atau 3 bulan sekali \\
\hline 10 & $\begin{array}{c}\text { Asim } \\
\text { Jumsinah }\end{array}$ & $\begin{array}{c}\text { Batujaya- Pasar Minggu } \\
\text { (Jakarta Selatan) } \\
\text { 2 Jam } 43 \text { Menit } \\
(142,2 \mathrm{~km})=(88,3062 \mathrm{Mil})\end{array}$ & 1 bulan sekali \\
\hline
\end{tabular}

Sampel 1 yaitu pasangan Diana Apriani dan Dikky. Pernikahan mereka sudah berlangsung selama 5 tahun, karena tuntutan pekerjaan, sehingga meskipun pasangan ini masih muda harus rela menjalani Long Distance Relationship(LDR).jika ia tinggal menetap bersama suaminya maka biaya kehidupan akan membengkak, mereka tidak dapat menabung, dan Diana juga telah bekerja sebagai pelayan toko di pasar Batujaya 
sehingga tidak dapat ikut dengan suaminya, intensitas pertemuan mereka yaitu 1 kali dalam sebulan Komunikasi keduanya melalui Telepon, SMS, Whatsapp dan Video Call. ${ }^{3}$

Sampel 2 yaitu pasangan Lita Safitri dan Andi Wijaya. Pernikahan mereka baru berusia 5 tahun dan telah dikaruniai seorang putra, alasan mendasar yang menyebabkan mereka menjalani Long Distance Relationship (LDR) yaitu karena faktor ekonomi, Andi bekerja sebagai buruh pabrik di pusat kota Karawang, waktu yang ditempuh dari pusat kota Karawang ke desa batujaya terbilang cukup dekat dan masih bisa pulang-pergi, tetapi cukup beresiko jika harus dilakukan setiap hari dan agar lebih hemat biaya, maka dia memutuskan untuk tinggal terpisah dengan istrinya, yaitu dengan mengontrak bersama teman-temannya, intensitas pertemuan antara keduanya berkisar 1 sampai 2 bulan sekali. Lita sebagai seorang istri tidak serta merta hanya menjadi ibu rumah tangga tetapi juga ikut untuk membantu perekonomian keluarga dengan berdagang makanan ringan. Cara komunikasi mereka melalui Telephone, Whatsapp, dan Video call. ${ }^{4}$

Sampel 3 pasangan Sanja dan Nurkinah, pernikahan mereka baru berusia 5 tahun dan telah dikaruniai seorang putra. Sanja bekerja sebagai pemulung di pasar minggu, alasannya menjalani Long Distance Relationship (LDR) yaitu karena istrinya telah memiliki pekerjaan sebagai penjaga toko di pasar Batujaya, sedangkan jika Nurkinah ikut tinggal bersama suaminya, dikhawatirkan susah mendapat pekerjaan serta biaya kehidupan disana lumayan besar, apalagi untuk biaya menyewa rumah, lebih baik uangnya ditabung untuk membuat rumah di desa. Mereka berkomunikasi melalui Telepon, Messenger, Whatsapp dan Video call. ${ }^{5}$

Sampel 4 yaitu pasangan Budi Kurniawan dan Yuliana yang telah menikah selama 8 tahun, keduanya tinggal secara terpisah karena pekerjaannya sebagai seorang chef di salah satu restoran di kota Jambi, memang sejak pacaran keduanya telah terbiasa menjalani Long Distance Relationship (LDR), sehingga Yuliana sebagai seorang isteri sudah sangat memaklumi dengan keadaan tersebut. Intensitas pertemuan antara keduanya hanya 1 sampai 2 kali dalam setahun yaitu ketika merayakan Hari Raya Idul Fitri dan Tahun Baru. Waktu pertemuan hanya sekitar 3 sampai 7 hari, untuk hari-hari biasa keduanya berkomunikasi melalui Telephone, Messenger, Whatsapp, sampai Video Call. ${ }^{6}$

Sampel 5 yaitu pasangan Jupri dan Sinta Dewi. Pernikahan mereka telah berlangsung selama 13 tahun, tidak berbeda dengan yang lain, Jupri pun menjadi seorang pemulung di daerah pasar minggu. Tuntutan pekerjaanlah yang menjadi alasan utama jupri dan Sinta Dewi menjalani Long Distance Relationship (LDR). Selain

\footnotetext{
${ }^{3}$ Hasil wawancara dengan Diana Apriani. Pada hari selasa, tanggal 02 Januari 2018. ${ }^{4}$ Hasil wawancara dengan Lita Sapitri. Pada hari Selasa, tanggal 02 Januari 2018. ${ }^{5}$ Hasil wawancara dengan Nurkinah. Pada hari selasa, tanggal 02 Januari 2018. ${ }^{6}$ Hasil wawancara dengan Yuliana. Pada hari selasa, tanggal 02 Januari 2018.
}

74 Jurnal Al-Ahwal Al-Syakhsiyyah : Jurnal Hukum Keluarga dan Peradilan Islam 
Reza Umami Zakiyah, Pola Pemenuhan Hak dan Kewajiban Suami Istri Long Distance Relationship ...

itu karena telah memiliki rumah sendiri di Batujaya, maka Sinta Dewi memilih untuk tetap tinggal dirumahnya agar lebih fokus dalam mengurus anak dan sesekali berdagang kue sebagai sampingan. Komunikasi mereka terjalin melalui telepon. ${ }^{7}$

Sampel 6 yaitu pasangan Danu Miharja dan Siti Khodijah. Pernikahan mereka telah berlangsung selama 14 tahun, Danu Miharja bekerja sebagai pemulung di daerah Tanggerang, mereka telah dikaruniai anak, alasan Danu Miharja dan Siti Khodijah memilih menjalani Long Distance Relationship (LDR) karena jarak antara Karawang Tanggerang cukup jauh jaraknya, sehingga Danu lebih memilih untuk mengontrak bersama teman-temannya. Siti Khodijah pun memilih untuk tetap tinggal dirumahnya (di Batujaya) untuk mengurus anak dan bekerja sebagai pedagang keliling. Komunikasinya melalui Telephone. ${ }^{8}$

Sampel 7 yaitu pasangan Sobari dan Rohayati yang telah menikah selama 19 tahun dan telah dikaruniai 3 orang anak, Sobari bekerja sebagai tukang bangunan di daerah Bogor, dan Rohayati bekerja sebagai tukang cuci, pertemuan keduanya yaitu 1 sampai 2 kali dalam setahun, itu pun jika ada libur panjang seperti Hari Raya Idul Fitri dan Tahun Baru. Mereka berkomunikasi melalui telepon milik putrinya, meski terbilang jarang karena jarang memiliki pulsa. ${ }^{9}$

Sampel 8 yaitu pasangan Japar dan Hamidah yang telah menikah selama 25 tahun, mereka telah memiliki dua orang putri. Putri pertamanya telah berkeluarga dan putri keduanya duduk dikelas 6 Sekolah Dasar (SD). Japar dan Hamidah telah bertahun-tahun menjalani kehidupan sebagai suami istri yang long distance Relationship (LDR), karena tuntutan pekerjaan sebagai seorang supir di pabrik, sehingga hamidah harus rela tinggal secara terpisah. Intensitas pertemuan keduanya yaitu 2 kali dalam seminggu, komunikasi mereka melalui Pesan singkat dan Telepon. ${ }^{10}$

Sampel 9 yaitu pasangan Subet dan Titi. Perrnikahan mereka sudah berlangsung selama 27 tahun dan telah memiliki 3 orang anak. Subet bekerja sebagai tukang bangunan di daerah Jakarta Pusat untuk program bedah rumah yang diselenggarakan oleh Rumah Zakat.Titi sendiri hanya sebagai Ibu Rumah Tangga, ketiga anaknya telah memiliki pasangan. Alasan utama menjalani Long distance Relationship (LDR) yaitu karena penghasilan yang diterima dari pekerjaanya sebagai tukang bangunan lebih besar di bandingkan dengan penghasilan sebelumnya yang diperoleh saat berjualan mie ayam di Batujaya. Komunikasi mereka terjalin melalui telepon, itupun sangat jarang. ${ }^{11}$

\footnotetext{
${ }^{7}$ Hasil wawancara dengan Sinta Dewi pada hari selasa tanggal 02 Januari 2018 ${ }^{8}$ Hasil wawancara dengan Siti Khodijah Pada hari selasa tanggal 02 Januari 2018 ${ }^{9}$ Hasil wawancara dengan Rohayati. Pada hari selasa, tanggal 02 Januari 2018. ${ }^{10}$ Hasil wawancara dengan Hamidah. Pada hari selasa, tanggal 02 Januari 2018. ${ }^{11}$ Hasil wawancara dengan Titi. Pada hari selasa, tanggal 02 Januari 2018.
} 
Sampel 10 yaitupasangan Asim dan Jumsinah. Usia pernikahan mereka telah mencapai 44 tahun, tetapi masih menjalani long distance Relationship (LDR). Tuntutan ekonomilah yang menjadi faktor utamanya. Asim bekerja di Jakarta sebagai pemulung, sedangkan istrinya Jumsinah bekerja menjaga warung dirumahnya. Intensitas pertemuan antara keduanya 1 sampai 2 bulan sekali, tergantung terkumpulnya uang yang telah dihasilkan. Komunikasi mereka melalui telepon. ${ }^{12}$

Setelah melihat kondisi diatas, maka menimbulkan banyak pertanyaan tentang bagaimana cara pasangan suami istri yang Long Distance Relationship (LDR) tetap dapat berkomunikasi dengan baik, dan jarak tidak menjadi suatu pemicu terjadinya pertengkaran, lalu bagaimanakah upaya mereka agar tetap harmonis dalam menjalankan pernikahannya.

\section{KEGUNAAN PENELITIAN}

Diharapkan penelitian ini dapat berguna khususnya bagi pengembangan pengetahuan dalam hukum islam dibidang Ahwal Syakhsiyah, yang berkaitan dengan pelaksanaan hak dan kewajiban suami istri dalam suatu pernikahan. Disamping itu, diharapkan penelitian ini dapat menarik minat peneliti lain, khususnya dikalangan mahasiswa untuk penelitian lanjutan tentang masalah yang sama atau serupa.

Setelah mencari dan mengumpulkan data yang berkaitan dengan pembahasan penelitian, tidak ditemukan penelitian ataupun karya ilmiah lainnya yang sama persis, namun peneliti menemukan beberapa karya ilmiah yang berhubungan dengan pembahaasan dalam penelitian ini, yang berbentuk skripsi dan tesis. Skripsi dan Thesis tersebut sama-sama berfokus pada kajian tentang Long Distance Relationship (LDR) dan Hak Kewajiban Suami Istri, tetapi yang membedakan antara penelitian penulis dengan penelitian lainnya yaitu dalam pembahasannya dengan memadukan antara teori-teori sosiologi yang ada dengan hukum dalam perundang-undangan yang berlaku dimasyarakat, sehingga antara fenomena yang terjadi dimasyarakat dengan hukum yang berlaku dapat berjalan beriringan, perbedaan lainnya yang sangat signifikan yaitu terlihat pada lokasi yang penulis pilih sebagai daerah penelitian, sudah jelas berbeda dari penelitian sebelumnya maka berbeda pula aspek sosial budaya didalamnya, yang diharapkan dari penelitian ini agar menambah variasi dalam penelitian yang mengangkat tema yaitu tentang Long Distance Relationship (LDR).

Penelitian ini menggabungkan 4 Teori yaitu : Teori Hak dan Kewajiban Suami Istri, Teori Perubahan dalam Keluarga, Teori Struktur Sosial dan Teori Komunikasi Interpersonal. Kemudian diolah bersama-sama melalui pembentukan proposisiproposisi dalam pemahaman, sebagai suatu pernyataan umum tentang hubungannya dengan fakta sosial yang ada.

${ }^{12}$ Hasil wawancara dengan Jumsinah. Pada hari selasa, tanggal 02 Januari 2018.

76 Jurnal Al-Ahwal Al-Syakhsiyyah : Jurnal Hukum Keluarga dan Peradilan Islam 
Reza Umami Zakiyah, Pola Pemenuhan Hak dan Kewajiban Suami Istri Long Distance Relationship ...

1. Teori Hak dan Kewajiban Suami Istri

Menurut ulama kontemporer Ali Khofif, hak adalah sebuah kemaslahatan yang boleh dimiliki secara syar'i. Menurut Mustafa Ahmad Zarqa, hak adalah suatu keistimewaan yang dengannya syara' menetapkan sebuah kewenangan atau sebuah beban $(\text { taklif })^{13}$. Sedangkan kewajiban adalah apa yang mesti dilakukan seseorang terhadap orang lain. Dalam hubungan suami istri, baik istri maupun suami telah memiliki hak dan mempunyai beberapa kewajiban ${ }^{14}$.Terkait hak dan kewajiban suami istri terdapat dua hak, yaitu kewajiban yang bersifat materil dan kewajiban yang bersifat immaterial. Bersifat materil berarti kewajiban Zahir atau yang merupakan harta benda, termasuk mahar dan nafkah. Sedangkan kewajiban yang bersifat immaterial adalah kewajiban batin seorang suami terhadap istri, seperti memimpin istri dan anakanaknya serta bergaul dengan istrinya.

2. Teori Perubahan sosial

Para ahli sejarah, filsafat, sosiologi dan ekonomi telah berusaha merumuskan prinsip atau hukum terhadap perubahan-perubahan sosial. Banyak pendapat yang mengatakan bahwa adanya kecenderungan perubahan sosial merupakan gejala wajar yang timbul dari pergaulan hidup manusia. Ahli lain berpendapat, perubahan sosial terjadi disebabkan perubahan dalam unsur-unsur yang mempertahankan keseimbangan masyarakat, seperti perubahan dalam unsur-unsur biologis, geografis, ekonomis atau kebudayaan. ${ }^{15}$ Begitupun dalam prakteknya, kehidupan suami istri ataupun keluarga banyak mengalami perubahan. Jika dahulu pasangan suami istri harus berdekatan secara fisik, dewasa ini pasangan suami istri yang bertemu di akhir pekan sudah menjadi hal yang lumrah.

Beberapa sosilog berpendapat bahwa terjadinya perubahan diakibatkan kondisikondisi sosial primer. Misalnya kondisi-kondisi ekonomis, teknologis, geografis atau biologis menyebabkan terjadinya perubahan-perubahan pada aspek kehidupan sosial lainnya. (William F. Obgurn menekankan pada kondisi teknologis).

3. Teori Struktur Sosial

Sedangkan Soerjono Soekanto melihat struktur sosial sebagai sebuah hubungan timbal balik antara posisi-posisi sosial serta peranan-peranan sosial. Sementara itu, Abdul Syani melihat struktur sosial sebagai sebuah tatanan sosial dalam kehidupan masyarakat. Di dalam tatanan sosial tersebut terkandung hubungan timbal balik antara status dan peranan (dengan batas-batas perangkat unsur-unsur sosial tertentu).

4. Teori Komunikasi Interpersonal

${ }^{13}$ Wahbah al-Zuhaili, Al-Fiqhu Al-Islamu Wa Adilatuhu (Beirut: Dar al-Fikr,1989),Jilid 4, h. 9

${ }^{14}$ Ahmad Rofiq, Hukum Perdata Islam di Indonesia (Jakarta: PT.Raja Grafika, 2013) h. 147.

${ }^{15}$ Soejono Soekanto, Budi Sulistyowati. Sosilogi Suatu Pengantar.(Jakarta:Rajawali Pers, 2017). Hlm. 
Komunikasi antarpribadi (Interpersonal communication) adalah komunikasi yang dilakukan secara tatap muka antara dua orang atau lebih, baik secara terorganisasi maupun pada kerumunan orang. Menurut Richard L. Weaver II(1993) Seperti yang telah dikutip oleh Budyatna mengatakan bahwa seperti salah satu karakteristik dari komunikasi antar pribadi yaitu : "Komunikasi tidak harus tatap muka. Bagi komunikasi antar pribadi yang sudah terbentuk, adanya saling pengertian antara dua individu, kehadiran fisik dalam berkomunikasi tidak terlalu penting" ${ }^{16}$

Komunikasi berlangsung untuk menjalin hubungan antar individu, individu dengan kelompok, dan kelompok dengan kelompok.Ikatan hubungan yang dapat berlangsung mendalam dapat ditemukan dalam konteks komunikasi antarpersonal (Interpersonal communication), dan dari berbagai macam komunikasi antar personal. Hubungan antara suami dengan istrilah yang paling berlangsung dalam, karena tidak hanya melibatkan semua hidupnya seperti pada hubungan keluarga dan Sahabat, tetapi juga melibatkan romantisme dan perasaan seksual.

\section{METODE PENELITIAN}

Metode penelitian ini adalah deskriptif analistis yaitu metode penelitian yang tujuannya memberikan suatu gambaran secara sistematis, faktual dan akurat mengenai fakta-fakta serta hubungan antara fenomena yang diselidiki untuk kemudian dianalisis. Suatu penelitian deskriptif dimaksudkan untuk memberikan data yang seteliti mungkin tentang manusia, keadaaan atau gejala-gejala lainnya. Selanjutnya dilakukan analisis terhadap hasil penelitian dengan menggunakan teori yang relevan melalui studi kepustakaan.

1. Sumber data

a. Data primer, yaitu hasil wawancara dengan para responden yaitu, pasangan suami istri LDR (Long Distance Relationship).

b. Data sekunder, yaitu literatur dan peraturan perundang-undangan yang ada kaitannya dengan masalah penelitian.

2. Jenis Data

Penelitian ini menggunakan jenis data kualitatif, yaitu data yang disajikan dalam bentuk kata verbal bukan dalam bentuk angka. Dalam penelitian ini jenis data yang dibutuhkan yaitu mengenai :

a. Cara pemenuhan hak dan kewajiban suami istri Long distance Relationship (LDR) di Dusun Batujaya, Desa Batujaya, Kec. Batujaya, Kab. Karawang.

b. Cara komunikasi suami istri Long distance Relationship (LDR) di Desa Batujaya, Kec. Batujaya, Kab. Karawang.

c. Cara mengatasi kesulitan rumah tangga yang timbul diantara keduanya.

${ }^{16}$ Muhammad Budyatna. Teori Komunikasi Antar Pribadi. Jakarta:Kencana,2011. Hlm. 156

78 Jurnal Al-Ahwal Al-Syakhsiyyah : Jurnal Hukum Keluarga dan Peradilan Islam 
Reza Umami Zakiyah, Pola Pemenuhan Hak dan Kewajiban Suami Istri Long Distance Relationship ...

3. Pengumpulan data

Adapun teknik pengumpulan data yang digunakan pada penelitian ini yaitu dengan cara sebagai berikut:
a. Observasi
b. Wawancara (Interview)
c. Studi Kepustakaan

4. Analisis Data

Data yang sudah terkumpul keduanya dianalisis dengan menggunakan pendekatan kualitatif, analisis dilakukan dengan melalui tahapan-tahapan sebagai berikut:

a. Mengumpulkan data dalam satuan-satuan sesuai dengan masalah yang diteliti.

b. Menelaah atau mengkategorikan semua data yang terkumpul dari berbagai sumber, baik sumber primer maupun sekunder.

c. Menghubungkan data dengan teori yang sudah dikemukakan dalam kerangka pemikiran.

d. Menafsirkan dan menarik kesimpulan dari data yang dianalisis dengan memperhatikan rumusan masalah-masalah dalam penelitian.

\section{HASIL PENELITIAN DAN PEMBAHASAN}

\section{Pola Pemenuhan Hak dan Kewajiban Suami Istri Long Distance Realitionship (LDR)} Aspek Finansial (Materi)

Dari data hasil wawancara bersama 10 informan maka dapat diketahui bahwa sebagian besar dari mereka cara pemenuhan kebutuhan finansial/materinya ada yang bertemu secara langsung atau tidak secara langsung misalnya melalui perantara teman atau melalui Alfamart/POS karena dirasa lebih mudah. cara ini biasa dilakukan oleh pasangan yang tidak memiliki ATM ataupun yang usianya sudah cukup tua dan bagi mereka yang suaminya bekerja selama 3 sampai 6 bulan maka lebih memilih mengirim uang melalui ATM.

Kebutuhan Biologis

Dari data hasil wawancara dengan 10 informan, 7 diantaranya memilih menggunakan alat bantu seperti handphone agar terasa lebih dekat dengan pasangan dan lebih mudah dalam menyalurkan hasratnya, yaitu dengan sex by phone. Selain itu untuk 3 informan lainnya, mereka memilih untuk lebih mendekatkan diri kepada Allah SWT dan menyibukkan diri dengan kegiatan-kegiatan yang lain, seperti mengerjakan pekerjaan rumah, menonton televisi atau bercengkrama bersama teman, anak-anak dan sanak saudara lainnya.

Aspek Psikologis. 
Dari data hasil wawancara dengan 10 informan maka dapat diketahui bahwa pola pemenuhan kebutuhan psikologis pada pasangan suami istri yang Long Distance Relationship (LDR) yaitu dengan memberikan perhatian lewat telepon atau pesan singkat misalnya, mengingatkan makan, mengingatkan sholat, dan mengungkapkan perasaan sayang. Kemudian dalam kehidupan sehari-harinya adanya sikap saling percaya, saling menjaga diri dan saling setia antar pasangan, karena hal ini juga termasuk kedalam pemenuhan kebutuhan psikologis. Dampak positif yang dirasakan jika kedua pasangan saling percaya, saling setia serta saling menjaga diri maka akan hal ini akan memperkecil resiko terjadinya percekcokan dalam suatu hubungan, sehingga terciptanya keharmonisan karena adanya kedamaian, kenyamanan dan rasa hangat dalam suatu hubungan.

\section{Cara Komunikasi Suami Istri Long Distance Realitionship (LDR)}

Sebagaimana data hasil wawancara dengan 10 informan yang menjalani Long Distance Relationship (LDR), maka dapat diketahui bahwa setiap pasangan memiliki caranya tersendiri dalam berkomunikasi dengan pasangannya. Misalnya pasangan yang memiliki alat komunikasi seperti handphone mereka dapat melakukan komunikasi secara intens, meskipun dalam keadaan sedang berjauhan, cara komunikasi mereka tidak hanya dapat dilakukan dengan mengirim pesan, menerima panggilan ataupun mengirim gambar, tetapi juga dapat berinteraksi melalui video call, sehingga mempermudah mereka dalam berkomunkasi. Tetapi untuk pasangan yang tidak menggunakan handphone, cara berkomunikasi mereka hanya dapat dilakukan secara langsung ketika mereka bertemu, yaitu pada saat suami mereka berada di rumah.

Dari 10 informan, maka dapat diketahui bahwa 3 di antaranya tidak menggunakan handphone sebagai alat bantu komunikasi, cara mereka dalam berkomunikasi yaitu melalui percakapan secara langsung pada saat bertemu dan pasangan yang tidak menggunakan alat bantu komunikasi pada saat menjalani Long Distance Relationship (LDR) lebih sedikit resiko perselisihannya karena waktu yang terbatas untuk bertemu membuat mereka lebih memilih menggunakan waktu kebersamaannya dengan sebaik-baiknya tanpa adanya pertengkaran ataupun sebagainya. Selanjutnya pada pasangan yang berkomunikasi menggunkan handphone, maka komunikasinya cenderung lebih intens dan lebih mudah, tetapi pada prakteknya tidak semua pasangan merasa puas, tetap saja ada kelemahannya misalnya masalah pada jaringan atau habisnya kuota atau pulsa, sehingga komunkasi tidak selamanya berjalan dengan lancar dan akibat kesibukan yang berbeda sehingga terkadang tidak menemukan waktu yang tepat untuk mengobrol sehingga sering terjadi kesalahpahaman.

\section{Cara Mengatasi Kesulitan Yang Timbul dari Suami Istri LDR}

80 Jurnal Al-Ahwal Al-Syakhsiyyah : Jurnal Hukum Keluarga dan Peradilan Islam 
Reza Umami Zakiyah, Pola Pemenuhan Hak dan Kewajiban Suami Istri Long Distance Relationship ...

Pasangan suami istri yang menjalani kehidupan rumah tangga Long Distance Relationship (LDR), memiliki cara tersendiri untuk mengatasi kesulitan yang terjadi dalam rumah tangganya yaitu dengan membangun komunikasi yang intensif dan membangun komitmen bersama pasangan. Untuk membangun sebuah komitmen dalam keadaan LDR pasti membutuhkan kepercayaan yang tinggi, kejujuran, dan kerjasama yang baik dengan pasangan dengan adanya kerjasama antara suami istri selama menjalani Long Distance Relationship (LDR), maka fungsi-fungsi penting dalam keluarga tetap terpenuhi dengan baik, selama masih ada kerjasama dan komitmen yang baik dari masing-masing pasangan.

Jadi dapat penulis pahami bahwa kesulitan-kesulitan yang sering muncul dalam kehidupan pernikahan pada pasangan yang Long Distance Relationship (LDR) salah satunya adalah masalah keuangan karena harus membiayai kebutuhannya dimana ia tinggal dan membiayai kebutuhan istri dan anaknya, lalu komunikasi yang tidak lancar karena terhambat oleh jaringan, kecurigaan yang timbul akibat tidak tinggal dalam satu atap, kemudian kurangnya kerjasama dalam mengurus rumah serta mengurus anak-anak dan masalah dalam pemenuhan kebutuhan seksual.

\section{SIMPULAN}

Pola pemenuhan hak dan kewajiban suami istri pada pasangan yang Long Distance Relationship (LDR) yaitu: Aspek finansial/materi yaitu dilakukan dengan 2 cara yaitu pertama, bertemu secara langsung. Kedua, Lewat perantara teman atau dengan cara mentransfer uang melalui Alfamart, ATM, ataupun POS. Aspek biologis yaitu ada yang secara langsung ataupun secara tidak langsung. Pola pemenuhan biologis secara langsung yaitu melalui hubungan intim pada saat keduanya bertemu dan cara pemenuhan kebutuhan biologis tidak langsung yaitu dengan cara menonton film dewasa, mengirim photo menggoda, dan sex by phone.

Aspek psikologis yaitu dengan memberikan perhatian dan kasih sayangnya dengan berkomunikasi melalui Handphone, sehingga dapat dengan mudah menanyakan keadaan masing-masuing, mengingatkan untuk menjaga kesehatan dan menjaga pola makan, serta menanyakan tentang pekerjan. Cara komunikasi yaitu Pertama, berkomunikasi secara langsung. Kedua, berkomunikasi secara tidak langsung.

Cara mengatasi kesulitan yaitu menjaga komitmen, saling percaya, saling setia, saling menghormati, menghargai, menguatkan satu sama lain, saling terbuka dalam segala hal, baik masalah keuangan ataupun masalah personal antar pasangan, berusaha menerima segala kekurangan pasangan serta saling kerjasama dalam mengurus rumah tangga, memanfaatkan sarana komunikasi yang tersedia, menyelesaikan masalah secara cepat dan berdoa kepada allah SWT agar selalu diberi kekuatan, bimbingan dan dijauhkan dari aneka godaan yang dapat mengganggu keharmonisan,. 


\section{DAFTAR PUSTAKA}

Ahmad Rofiq, Hukum Perdata Islam di Indonesia (Jakarta: PT.Raja Grafika, 2013) h. 147. David, P, Hampton, JR. (2004). "The Effect od Communication On Satisfaction In Long Distance And Proximal Relationships Of College Students". Chicago: Loyola University. Diakses dari http://www.webclearinghouse.net/volume/4/HAM PTON-TheEffecto.php. Pada tanggal 13 mei 2018 pukul 11.15 WIB.

Muhammad Budyatna. Teori Komunikasi Antar Pribadi. Jakarta:Kencana,2011. Hlm. 156

Soejono Soekanto, Budi Sulistyowati. Sosilogi Suatu Pengantar.(Jakarta:Rajawali Pers, 2017). Hlm. 261

Thomas, J. Kidenda,(2002)." A Study of culture variability andrelational maintenance beharviors forinternational and domestic proximal and long distance interpersonal relationship", (Doctoral Dissertation) Diakses dari https://scholar.google.co.id/ scholar $/ \mathrm{hl}=\mathrm{id} \& a s \quad \mathrm{sdt}=0 \% 2 \mathrm{C} 5 \& \mathrm{q}=\mathrm{kidenda+t.j+a+study+of+ \text {culture } + \text { variability } + \text { an }}$ drelational\&btnG=\#d=g qabs\&p=\&u=\%23p\%3Do6rVg5TLibgjs, Pada Tanggal 13 Mei 2018 Pukul 10.47 WIB.

Wahbah al-Zuhaili, Al-Fiqhu Al-Islamu Wa Adilatuhu (Beirut: Dar al-Fikr,1989),Jilid 4, h.9 